\title{
GPS Monitoring in the N-W Part of the Volcanic Island of Tenerife, Canaries, Spain: Strategy and Results
}

\author{
J. Fernández ，F. J. González-Matesanz , J. F. Prieto , \\ G. Rodríguez-Velasco, A. Staller,
}

A. Alonso-Medina, and M. Charco

\begin{abstract}
This paper describes design, observation methodology, results and interpretation of the GPS surveys conducted in the areas of the N-W of Tenerife where deformation was detected using InSAR. To avoid undesirable antenna positioning errors in the stations built using nails, we designed and used calibrated, fixed-length metal poles, allowing us to guarantee that the GPS antenna was stationed with a height repeatability of the order of $1 \mathrm{~mm}$ and of less than 3 millimeters on the horizontal plane. The results demonstrate that this system is ideal for field observation, especially to detect small displacements that might be masked by accidental errors in height measurements or centering when observed with a tripod. When observations were processed, we found that using different antenna models in the same session sometimes causes errors that can lead to rather inaccurate results. We also found that it is advisable to observe one or two stations in all the sessions. The results have reconfirmed the displacement in the Chío deformation zone for the period 1995-2000 and indicate a vertical rebound from 2000 to 2002. They also confirm that the subsidence detected by InSAR to the south of the Garachico village has continued since 2000, although the magnitude of the vertical deformation has increased from around $1 \mathrm{~cm}$ to more than $3 \mathrm{~cm}$ a year. Detected displacements could be due to groundwater level variation throughout the island. A first attempt of modelling has been made using a simple model. The results indicate that the observed deformation and the groundwater level variation are related in some way. The obtained results are very important because they might affect the design of the geodetic monitoring of volcanic reactivation on the island, which will only be actually useful if it is capable of distinguishing between displacements that might be linked to volcanic activity and those produced by other causes. Even though the study was limited to a given area of Tenerife, in the Canary Islands, some conclusions apply to, and are of general interest in similar geodynamic studies.
\end{abstract}

Key words: Tenerife, Canary Islands, geodetic volcano monitoring, GPS, InSAR. 


\section{Introduction}

Although geodetic monitoring techniques have been widely used in areas of seismic or volcanic activity, the difficulty inherent to their discrete nature means that they must be deployed carefully to ensure the best possible detection or sensitivity of these points (see e.g., BALDI and UNGUENDOLI, 1987; JOHNSON and WYATT, 1994; SEgall and MatThews, 1997; YU et al., 2000). In many cases, a more global monitoring method, is required yet at the same time one that offers the highest level of sensitivity which enables detection of the phenomenon. Interferometry radar (InSAR) techniques have been shown to play an important role in seismic and volcanic monitoring because they cover large areas $(100 \times 100 \mathrm{~km})$ and can be easily systematized in monitoring (see e.g., MASSONNET and FEIGL, 1998; BÜrGMANN et al., 2000; Massonnet and Sigmundson, 2000; HAnssen, 2001). The limitations inherent to the GPS and InSAR techniques (mainly observations at discrete surface points in the case of GPS and existence of non-coherent areas and the fact that, at present, the three displacement components cannot be obtained in SAR interferometry) can be overcome by using them together or other techniques (e.g., PUGlisi and Coltelli, 2001; Rodríguez-VElAsCo et al., 2002; FERNÁNDEZ et al., 2003).

The Canary Islands are seven islands and several islets of volcanic origin located between parallels $27^{\circ}$ and $30^{\circ}$ latitude North and between the parallels $13^{\circ}$ and $19^{\circ}$ longitude West. Located less than $100 \mathrm{~km}$ from the African continent, the Canary Islands were formed on the continental rise and slope as independent structures (ARAÑA and ORTíz, 1991). Despite being on a passive margin, they form a volcanic archipelago with a long-standing history of volcanic activity that began more than 40 m.y. ago (ANCOCHEA et al., 1990). At least a dozen eruptions occurred on the islands of Lanzarote, Tenerife, and La Palma between 1500 and 1971. Tenerife, the biggest island of the Archipelago, and its eruptive system are dominated by the Teide (3718 m) (ABLAY and MARTí, 2000) and Las Cañadas Caldera (MARTí et al., 1994). At the northern border of this caldera the Teide strato-volcano has been formed over the last one hundred and fifty thousand years. One of the most important eruptions took place in 1706 (Arenas Negras volcano) and destroyed part of Garachico village. Las Cañadas Caldera and the Teide are the areas where most volcanic research, in particular geodetic measurements (e.g., SEvilla and Romero, 1991; CAMACHo et al., 1991), has been performed without any significant displacement or gravity changes having been detected to date.

Interferometry Synthetic Aperture Radar (InSAR) has been used to monitor the island of Tenerife during the period 1992-2000 (CARRASCO et al., 2000; FERNÁNDEZ et al., 2002). This technique can be used to cover the whole island in a single interferogram and obtain fairly comprehensive information about possible deformation in areas with a high level of coherence. The analysis of the interferograms revealed two areas with deformation: subsidence (see e.g., FERNÁndEZ et al., 2002), located to the south of Garachico (an area of approximately $15 \mathrm{~km}^{2}$ with a maximum 
subsidence of $10 \mathrm{~cm}$ from 1993 to 2000) and the Pinar de Chío zone (an area of approximately $8 \mathrm{~km}^{2}$ with a maximum subsidence of $3 \mathrm{~cm}$ from 1993 to 2000, with a faster displacement velocity since 1997, see CARRASCO et al. (2000)). The location of these areas is displayed in Figure 1. From now on, we will refer to the two areas as Deformation Zones (DZs) and DZ1 and DZ2, respectively. However, they were unable to obtain information about possible displacements throughout the island, because although the whole island fits in one SAR image, the level of coherence is not good over the entire surface. In fact, in some areas there is no coherence at all (FERNÁNDEZ et al., 2002, 2003). Therefore another technique, GPS, had to be used to monitor these areas, and to validate the deformations detected. We defined a GPS network that covered the entire island, which was densified in the areas of

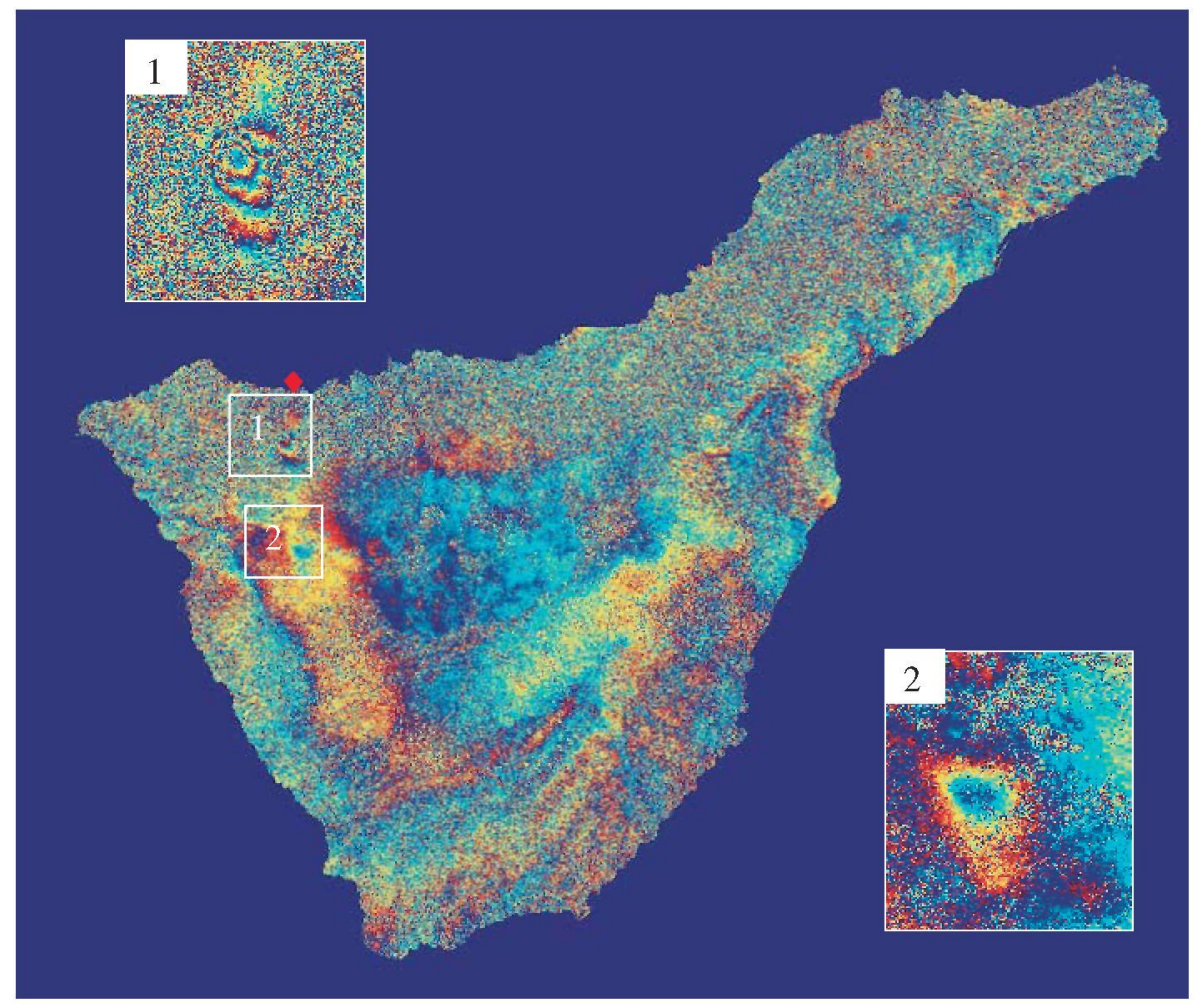

Figure 1

Differential interferogram from Tenerife island corresponding to 2 Aug. 1996-15 Sept. 2000. No fringe can be seen in the Las Cañadas area, so there is no deformation from 2 Aug. 1996-15 Sept. 2000 1) and 2) represent Garachico and Chío subsidence, respectively, from 20 Jul. 1993-15 Sept. 2000 differential interferogram $\left(\mathrm{B}_{\perp}=180 \mathrm{~m}, \Delta d=2614\right.$ days). The Garachico subsidence has 3 fringes, in other words, about $9 \mathrm{~cm}$ of ground subsidence from 20 Jul. 1993-15 Sept. 2000; the Chío subsidence has 1 fringe, that is to say, about $3 \mathrm{~cm}$ of ground subsidence from $20 \mathrm{Jul}$. 1993-15 Sept. 2000.

indicates the location of Garachico village. 
deformation detected with InSAR. This network was observed in 2000 and the obtained results (RODRÍGUEZ-VELASCO et al., 2002; FERNÁNDEZ et al., 2003) allowed us to validate the deformation found in Pinar de Chío, but not the one found to the south of the town of Garachico. Furthermore, certain antenna-height measuring problems were encountered in certain stations observed with tripods. To solve these two aspects we designed a micro-GPS network covering both deformation areas located in the N-W part of the Volcanic Island of Tenerife and modified the observation methodology.

This paper briefly describes the design of the campaigns, the observation methodology used, the results of the campaigns conducted in 2000, 2001 and 2002, the conclusions obtained when these results were compared with the results of a previous campaign and from InSAR, as well as a first tentative interpretation.

\section{2000 GPS campaigh}

Even though one of the characteristics associated with volcanic activity in Tenerife is that eruptions normally have not occurred more than once in the same volcanic structures, the geodetic monitoring conducted until 2000 was focused mainly on the Caldera de Las Cañadas, where a geodetic micronetwork and a levelling profile have been installed (SEvilla and Romero, 1991; Sevilla et al., 1996). This is because the biggest volcanic risk on the island is associated with the Teide stratovolcano located in the Caldera. A sensitivity test of this geodetic network showed a clear need to extend the existing geodetic network to cover the full island for volcano monitoring purposes using GPS techniques (YU et al., 2000). This conclusion, together with the detection of two unexpected movements on the island, by the processing of Synthetic Aperture Radar (SAR) data that were beyond the scope of the traditional geodetic network installed on the island due to coverage limitations, prompted us to design and observe a GPS network covering entirely Tenerife in 2000, mainly for the purposes of the geodetic monitoring of possible displacements associated with volcanic reactivation and corroborating the obtained results by InSAR. This GPS network has a station in DZ2 and a densification in DZ1 located to the south of the village of Garachico (Fig. 2). The network and its densification was observed in August 2000 using 5 receivers and relative static observations (HOFMANN-WeLleNHOF et al., 1992) during periods of 5 and 2 hours, depending on the baseline length.

The data collected for the global network and DZ1 densification during the 2000 survey were processed separately using Bernese 4.2 software (BEUTLER et al., 2001) with precise ephemeredes. To fully guarantee that the results were included in the REGCAN-95 reference system (CATURLA, 1996), based on the ITRF93 date 94.9 (where we have previous values of coordinates for many of the stations), Chinobre, Teide and Bocinegro stations were considered fixed in the GPS observation process. 


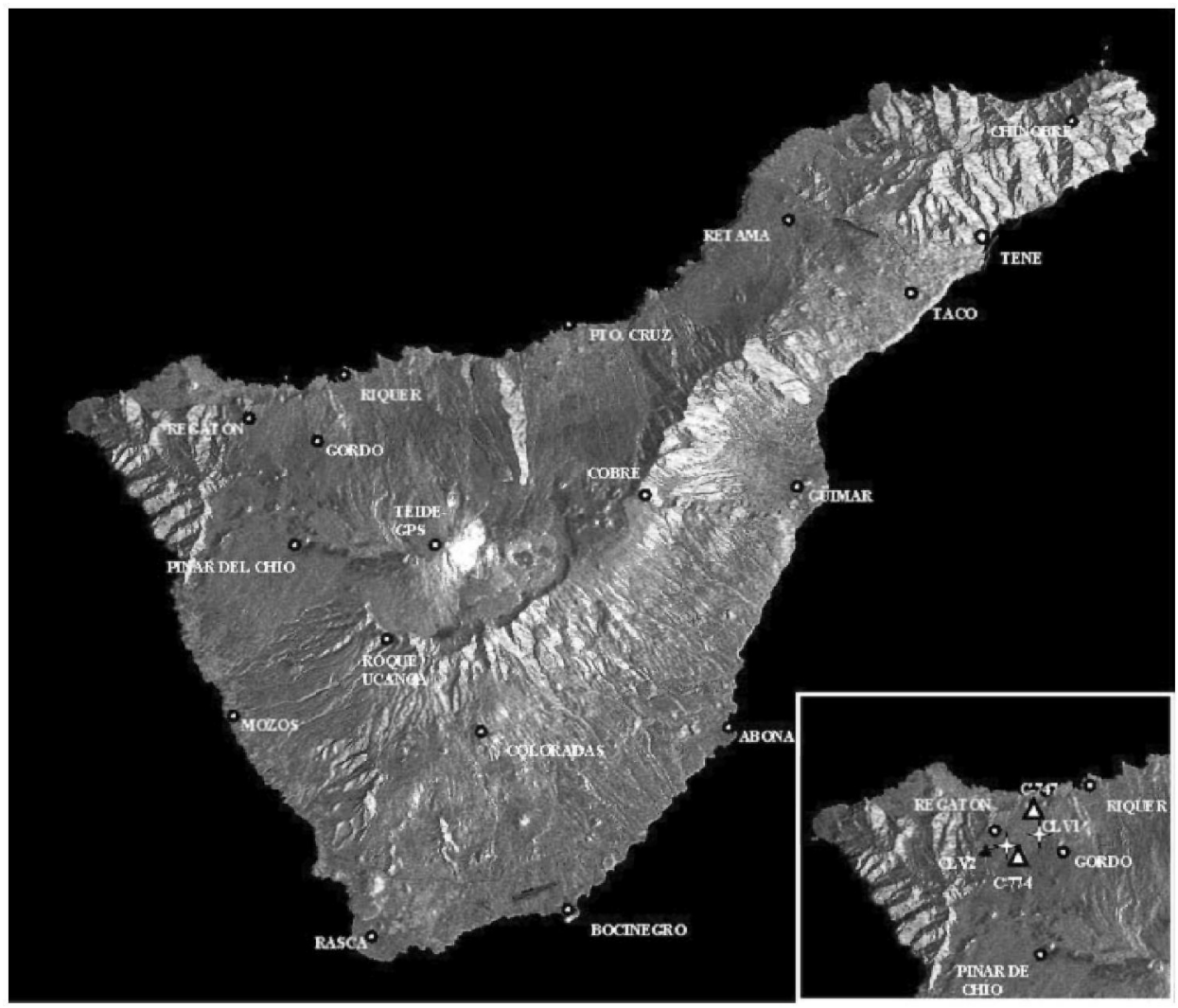

Figure 2

Global GPS network: 17 stations from REGCAN95 together with the permanent station TENE, marked with white circles. A densification network sketch appears on the bottom right. It is formed by 2 fourthorder stations (white triangles) and 2 benchmarks (white stars) (after FERNÁNDEZ et al., 2003).

Regatón station, near DZ1, was used as a fixed reference station in that zone's subnetwork. The precision of the obtained results is within one centimeter in height and several millimeters in horizontal coordinates. For more details see RoDríguEzVELASCO et al. (2002) and FERNÁNDEZ et al. (2003). Significant coordinate variations were obtained in several stations distributed throughout the island, showing a subsidence of station Pinar de Chío, of the same order as obtained using InSAR in DZ2. Therefore the two techniques have confirmed one another. Some coordinate variations were detected in areas where the band $C$ radar observation cannot be used for deformation monitoring on account of the very low coherence, due to the existence of vegetation. This demonstrates that the two techniques complement one another, and that they should be combined in any monitoring methodology that is to be efficient in detecting possible deformations associated with volcanic reactivation on the island. 
The obtained results in the DZ1, to the south of the town of Garachico, were not definitive enough to confirm the displacements detected using InSAR (see RoDRÍGUEZ-VELASCO et al., 2002; FERNÁNDEZ et al., 2003). Future observations were considered necessary and more stations would have to be included in this DZ1, preferably in the center where the largest deformation occurs and is therefore easier to detect. Furthermore, it must be taken into account that several stations in the deformation zone were observed with a tripod, and therefore the antenna height measurements and centering might contain inaccuracies that should be eliminated as far as possible, considering the magnitude of the vertical displacement (of the order of one cm, as shown by InSAR results for the 1993-2000 period) that is to be detected.

\section{2001 GPS Campaign}

In an attempt to solve the aforementioned problems, we designed and observed a micro-GPS network limited to the DZs. This micro-network is formed by four vertices of the REGCAN95, run by the National Geographic Institute of Spain (IGN) (CATURLA, 1996), two benchmarks of the fourth-order network and three nails located in the deformation zone, Figure 3a. Geodetic vertices of the REGCAN95 network Riquer, Regatón and Roque de Ucanca were selected as reference stations because they were regarded as located outside the DZs. When this micro-network was being designed, and taking into consideration the obtained results in the 2000 campaign, a new station was added in the center of DZ1, CLAVO3 (CLV3 in Fig. 3a).

For the nails we designed fixed-length poles which were perfectly numbered and calibrated, and secured them with steel cable by means of a turnbuckle and a galvanized flat (Fig. 4). The aim was to avoid having to measure the antenna height in this and future campaigns, thus eliminating a frequent source of errors. Using these poles let us assure a height repeatability of the order of $1 \mathrm{~mm}$. Each pole is formed by a stainless steel pipe 1.125 meters high and $3 \mathrm{~cm}$ in diameter. The accidental errors in component $x$ and $y$ caused by levelling the pole remain below 3 millimeters due to the use of a $10^{\prime}$ level and to the fact that the pole is fastened with steel guys (see Fig. 4).

The GPS observation of the micro-network conducted in 2001 took account of the following aspects: minimum observation period of 4 hours in morning and afternoon sessions for baselines between 0.8 and $20 \mathrm{~km}$; use of 4 simultaneous receivers; CLAVO 3 station, located in the center of the deformation zone, was observed in all the sessions (except in the first, due to an antenna problem). The observation sessions are summarised in Table 1.

In order to facilitate the comparison of results, the data collected were processed as 2000 data, using Bernese 4.2 software. To guarantee that our results were included 

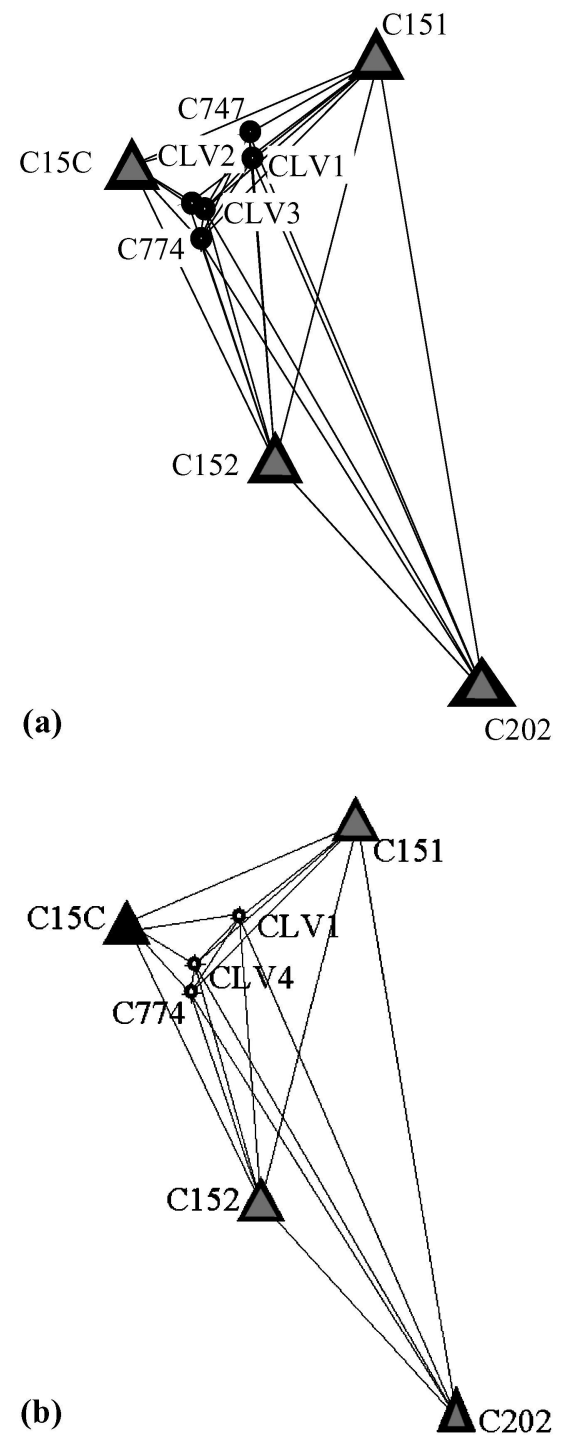

Figure 3

(a) 2001 and (b) 2002 GPS micro-networks.

in the REGCAN-95 reference system, in the GPS observation process we established the Regatón station $(\mathrm{C} 15 \mathrm{C})$, near $\mathrm{DZ} 1$, as a fixed station to the coordinates determined in the 2000 GPS campaign (FERNÁNDEZ et al., 2003).

The data analysis demonstrated that a set of GPS vectors were obtained at the C151 Riquer station grouped in the three sessions in which the GPS antenna was located at that station throughout the campaign. The values of the altitudes assigned 


\section{GPS ANTENNA POLE}

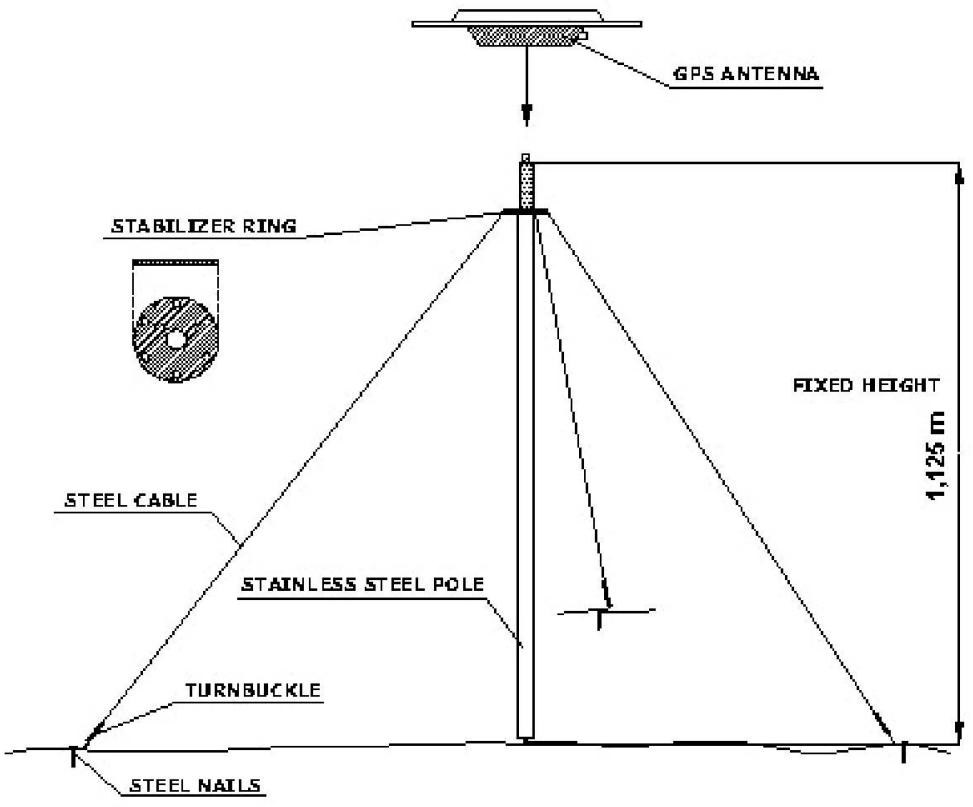

(a)

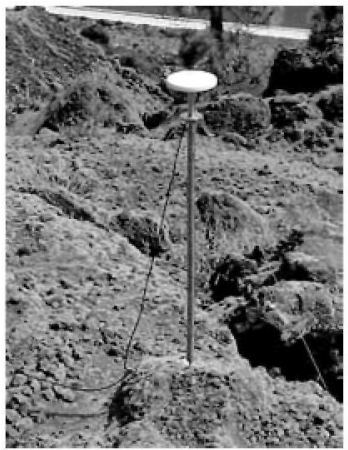

(b)

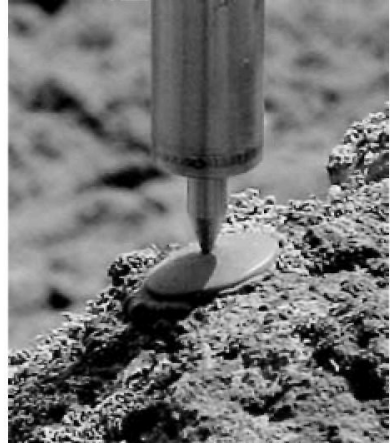

(c)

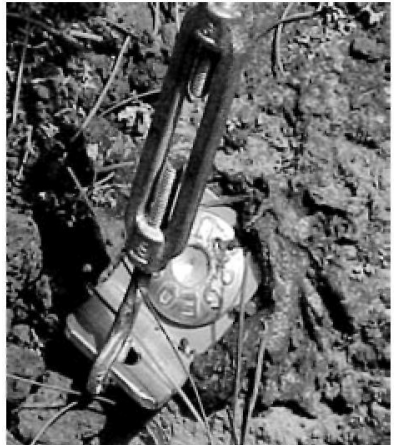

(d)

Figure 4

(a) Scheme of the steel pole for observation in benchmarks, (b) steel pole at benchmark 774, (c) pole end, and (d) hook and eye turnbuckle.

to Riquer by the vectors of the first two sessions were grouped around values that only differ by a few $\mathrm{mm}$, but differing from the value of the altitude assigned by the third session by around eight centimeters. Different tests were conducted to study its 
Table 1

(a) Surveys carried out in 2001 and 2002 of the geodetic GPS network in Tenerife; (b) distribución de stations observed at the different sessions

(a)

\begin{tabular}{|c|c|c|c|c|c|c|c|c|c|}
\hline Year & From & To & Sessions & Duration & Receivers & Stations & Baselines & Parameters & Observations \\
\hline 2001 & 26 Jul. & $30 \mathrm{Jul}$. & 5 & 4 or 8 hours & 4 & 9 & 19 & 366 & 8808 \\
\hline 2002 & $25 \mathrm{Jul}$. & $29 \mathrm{Jul}$. & 5 & 6 hours & 5 & 7 & 20 & 394 & 13932 \\
\hline
\end{tabular}

(b)

\begin{tabular}{|c|c|c|c|c|c|c|c|c|c|c|}
\hline \multicolumn{11}{|c|}{ OBSERVATION OF STATIONS } \\
\hline \multirow[t]{2}{*}{ STATION } & \multicolumn{5}{|c|}{2001 SESSIONS } & \multicolumn{5}{|c|}{2002 SESSIONS } \\
\hline & 1 & 2 & 3 & 4 & 5 & 1 & 2 & 3 & 4 & 5 \\
\hline $\mathrm{C} 202$ & $\mathrm{X}$ & $X$ & & & $\mathrm{X}$ & $\mathrm{X}$ & & $\mathrm{X}$ & $\mathrm{X}$ & \\
\hline C774 & $X$ & $X$ & & X & $\mathrm{X}$ & $X$ & $\mathrm{X}$ & & $\mathrm{X}$ & \\
\hline C152 & $X$ & $X$ & & X & $\mathrm{X}$ & $X$ & & $\mathrm{X}$ & & $\mathrm{X}$ \\
\hline C747 & & $\mathrm{X}$ & $\mathrm{X}$ & & $\mathrm{X}$ & & & & & \\
\hline C151 & & $\mathrm{X}$ & $\mathrm{X}$ & & $\mathrm{X}$ & & $\mathrm{X}$ & & $\mathrm{X}$ & $\mathrm{X}$ \\
\hline CLV3 & & $\mathrm{X}$ & $\mathrm{X}$ & X & $\mathrm{X}$ & & & & & \\
\hline $\mathrm{C} 15 \mathrm{C}$ & & & $\mathrm{X}$ & X & & $\mathrm{X}$ & $\mathrm{X}$ & $X$ & $\mathrm{X}$ & $\mathrm{X}$ \\
\hline CLV2 & & & $\mathrm{X}$ & $\mathrm{X}$ & & & & & & \\
\hline CLV1 & & & & & $\mathrm{X}$ & & $\mathrm{X}$ & $\mathrm{X}$ & & $\mathrm{X}$ \\
\hline CLV4 & & & & & & X & $\mathrm{X}$ & $\mathrm{X}$ & $\mathrm{X}$ & X \\
\hline
\end{tabular}

effect: in (a), we processed the data considering the Riquer observations in the three sessions in which the station was used; in (b) we only considered the first two sessions in Riquer, observed with the same antenna; in (c) we only considered the last day and in (d) we used none of the observations in this station. The obtained results in the four cases using Bernese 4.2 were similar (in terms of level of precision) for all the points except Riquer. When these results are compared with the rest of the GPS network in a constraint-free adjustment (LEICK, 1990), and conducting the pertinent tests to detect gross errors, the observations made in the first two sessions are rejected, although it is significant to note that both are grouped around values that only differ by a few millimeters, as mentioned above. The network adjustment indicates that the most coherent solution for station $\mathrm{C} 151$ is the one provided by the third session, case (c), yet the fact that the rejected sessions are grouped independently and separately inclines one to think that this station's results should not be considered definitive until a redundancy of results higher than the one found in the 2001 campaign is obtained for this station.

After the 2001 campaign we concluded that further campaigns should be conducted with the same methodology, although using the same model of geodetic antennae in all the stations and sessions to avoid causing any noise in the level of 
detection required in this work, close to the precision that the technique can provide without permanent observation.

\section{2002 GPS Campaign}

The 2002 campaign was based on the main conclusions drawn from the results of the 2001 campaign. However, during the inspection prior to the observations, we found that two benchmarks, CLV2 and CLV3, had been destroyed. In an attempt to solve the problem caused by the disappearance of station CLV3, located in the middle of DZ1, and considering future campaigns, we installed another nail nearby at a location that was named CLAVO4, CLV4.

In the observation we used the same geodetic antenna model for all stations and sessions. Station $\mathrm{C} 15 \mathrm{C}$, considered fixed in the data processing, and the new station CLV4 were observed in all the sessions. Figure $3 \mathrm{~b}$ is a diagram of the micro-network. The observation characteristics are also given in Table 1. The data processing was performed in exactly the way as in the 2000 and 2001 campaigns. The obtained results are given in Table 3 .

\section{Discussion of Results and Interpretation}

The results of the 2001 and 2002 surveys can be compared with those obtained in 1995 and 2000 (see FERNÁNDEZ et al., 2003) at the coinciding points. The differences are shown graphically in Figure 5. The comparison of the 2001 coordinates recorded at the Pinar de Chío station, C152, to the 1995 coordinates

Table 2

Coordinates of the DZs micro-network stations observed during the 2001 campaign, determined in the REGCAN95 system. Precision in meters. The Regatón station, whose coordinates have not been assigned a level of precision, has been considered fixed. See text for more details

\begin{tabular}{|c|c|c|c|c|}
\hline \multicolumn{2}{|l|}{ STATION } & LATITUDE & LONGITUDE & \multirow{2}{*}{$\begin{array}{c}\text { ELLIPSOIDAL } \\
\text { HEIGHT } \\
\text { (m) }\end{array}$} \\
\hline NAME & CODE & & $\therefore)$ & \\
\hline RIQUER & $\mathrm{C} 151$ & $282248.04568 \pm 0.001$ & $-164302.53895 \pm 0.001$ & $209.999 \pm 0.006$ \\
\hline PINAR DE CHIO & $\mathrm{C} 152$ & $281608.36172 \pm 0.001$ & $-164458.32698 \pm 0.001$ & $1641.354 \pm 0.003$ \\
\hline ROQUE DE UCANCA & $\mathrm{C} 202$ & $281219.98654 \pm 0.001$ & $-164100.29192 \pm 0.001$ & $2155.187 \pm 0.004$ \\
\hline REGATÓN & $\mathrm{C} 15 \mathrm{C}$ & 282102.65978 & -164739.10352 & 844.727 \\
\hline 747 & $\mathrm{C} 747$ & $282134.86858 \pm 0.001$ & $-164527.61258 \pm 0.001$ & $652.729 \pm 0.004$ \\
\hline 774 & $\mathrm{C} 774$ & $281948.21827 \pm 0.001$ & $-164621.66942 \pm 0.001$ & $1129.869 \pm 0.004$ \\
\hline CLAVO 1 & CLV1 & $282108.98676 \pm 0.001$ & $-164523.28204 \pm 0.001$ & $766.721 \pm 0.004$ \\
\hline CLAVO 2 & CLV2 & $282024.72778 \pm 0.001$ & $-164635.23842 \pm 0.001$ & $954.600 \pm 0.004$ \\
\hline CLAVO 3 & CLV3 & $282018.64512 \pm 0.001$ & $-164617.08318 \pm 0.001$ & $990.585 \pm 0.003$ \\
\hline
\end{tabular}


Table 3

Coordinates of the DZs micro-network stations observed during the 2002 campaign, determined in the REGCAN95 system. Precision in meters. The Regatón station, whose coordinates have not been assigned a level of precision, has been considered fixed. See text for more details

\begin{tabular}{|c|c|c|c|c|}
\hline \multicolumn{2}{|l|}{ STATION } & \multirow[t]{2}{*}{ LATITUDE } & \multirow[t]{2}{*}{ LONGITUDE } & \multirow{2}{*}{$\begin{array}{c}\text { ELLIPSOIDAL } \\
\text { HEIGHT } \\
(\mathrm{m})\end{array}$} \\
\hline NAME & $\mathrm{CODE}$ & & & \\
\hline & & 0.001 & -1643 & 209.975 \\
\hline PINAR D & & 001 & -164 & $1641.383 \pm 0.003$ \\
\hline ROQUE DE UCANCA & $\mathrm{C} 202$ & $281219.98621 \pm 0.001$ & $-164100.29171 \pm 0.001$ & $2155.185 \pm 0.003$ \\
\hline REGATÓN & $\mathrm{C} 15 \mathrm{C}$ & 282102.65978 & -164739.10352 & 844.727 \\
\hline 774 & C774 & $281948.21778 \pm 0.001$ & $-164621.66912 \pm 0.001$ & $1129.812 \pm 0.003$ \\
\hline CLAVC & CLV1 & $282108.98671 \pm 0.001$ & $-164523.28239 \pm 0.001$ & $766.699 \pm 0.003$ \\
\hline CLAVO 4 & CLV4 & $282018.56635 \pm 0.001$ & $-164615.20997 \pm 0.001$ & $996.058 \pm 0.003$ \\
\hline
\end{tabular}

confirmed the subsidence obtained results by InSAR. The difference is larger, albeit only slightly, than $2 \sigma$. We also obtained horizontal displacements of around one $\mathrm{cm}$ in the $\mathrm{N}-\mathrm{W}$ direction. The vertical deformation obtained results upon comparing the values of 2000 and 2001 are not significant, as was to be expected, taking into account the InSAR results (approximately $3 \mathrm{~cm}$ of deformation in eight years). In this second case of comparison, the horizontal deformation results are significant again in the $\mathrm{N}-\mathrm{W}$ direction. However the real magnitude of the horizontal displacement might be smaller due to the possibility of errors in the antenna centering, because in 2000 this station was observed without a tribrach due to availability problems on the observation day. Comparing the 2002 and 1995 coordinates shows the height values to be quite identical, with differences below precision level. Horizontal displacement is still N-W, increasing in magnitude to the $\mathrm{N}$ and decreasing to the $\mathrm{W}$. If one compares 2002 with 2000 , the horizontal displacement is still N-W, but compared to the results for 2001 the displacement is N-E. In short, vertical displacement at the Pinar de Chio station, see Figure 5, indicates clear subsidence from 1995 to 2000 (coinciding with InSAR results) and elevation from 2000 to 2002 .

At the Roque de Ucanca station, when the 1995 coordinates were compared with the 2001 coordinates, the vertical and horizontal differences were around $2 \sigma$, and could not be considered clearly significant. The vertical differences found upon comparing 2000 and 2001 are not significant either, although the horizontal ones are. Comparing the 2002 height with the values for 1995, 2000 and 2001 gives similar results, a tendency showing subsidence, though not significant over the noise level. The horizontal components display a N-W displacement, as in Pinar de Chío. Therefore new campaigns must be conducted in order to look for possible displacement at this station, which is next to $\mathrm{C} 152$ and could also be starting to display displacements. Therefore this point must be studied very carefully in future campaigns. 
In the fourth order pin $\mathrm{C} 774$, the vertical coordinate variations in the comparison of 2000, 2001 and 2002 with respect to 1995 were not significant because the 1995 coordinates were not very accurate. Comparison between 2000 and 2001 results are not significant either, but comparing 2002 with 2000 and 2001 values produces clearly significant subsidence. Comparing the 2000 coordinates with 2001 and 2002 reveals horizontal displacement in the $\mathrm{S}-\mathrm{W}$ direction, although one must remember that the 2000 observation might contain a centering error. Comparing the 2002 and 2001 reveals $\mathrm{N}-\mathrm{W}$ displacement.

At pin 747 the vertical coordinate differences include an uplifting of $5.7 \mathrm{~cm}$ in the 95-00 period, an uplifting of $1.8 \mathrm{~cm}$ in the period $95-01$, and a subsidence of $3.9 \mathrm{~cm}$ in the period 00-01. Comparing the 1995 and 2000 coordinates reveals E-W displacement that is also observed in the period 2000-2001. The station is located on the roof of a small water tank, the height of which more than probably varies in line with the level of water in the tank. In fact, at first it was thought that the tank was no longer in use, and it was chosen due to its proximity to the $\mathrm{DZ}$ and because it offered previous coordinates with which to make comparisons. The obtained results, together with the inspections carried out subsequently (FERNÁNDEZ et al., 2003) have shown that the tank is still being used and that the level of water inside is far from constant. Therefore, and also taking into account that when the station is accurately located, it is clearly outside the DZ, we can conclude that the choice of the point was unfortunate and the variation of its coordinates is far from significant. This benchmark was removed from the network in the 2002 observations.

At stations Clavo1 and Clavo2, CLV1 and CLV2, respectively, if we compare the 2001 and 2000 coordinates, the vertical coordinate differences are not significant as they are less than $2 \sigma$ or very close, and we must consider the more than probable existence of accidental errors in the antenna height-measuring in the 2000 observation with tripods. Due to its disappearance, CLV2 was not observed in 2002. If we compare the 2002 coordinates of CLV1 with the 2000 and 2001 values, see Figure 5, we observe a clear and significant subsidence, and if we do not consider horizontal coordinates from 2000 , which might contain centring errors due to the use of tripods, there is also clear horizontal displacement in the E direction.

At station Riquer, C151, without considering the results for 2001, due to the aforementioned problem, a clear subsidence and a $\mathrm{N}-\mathrm{W}$ displacement is observed, see Table 2.

Apart from the need to check certain stations, one question that remains is to determine the possible causes of the subsidence detected. These causes could differ widely from one area to another: compacting of the lava emitted during the last eruptions, subduction post eruptions caused by the emptiness of the magma chambers, volcanic reactivation, this subsidence could be caused by a dyke (Yu et al., 2000 ), or the extraction of water from water tables. It must be stressed that numerous tunnels have been drilled in the subsoil of most of the island to draw drinking water for the island's inhabitants (GobIERnO DE CANARIAS and CABILdo INSUlar DE 

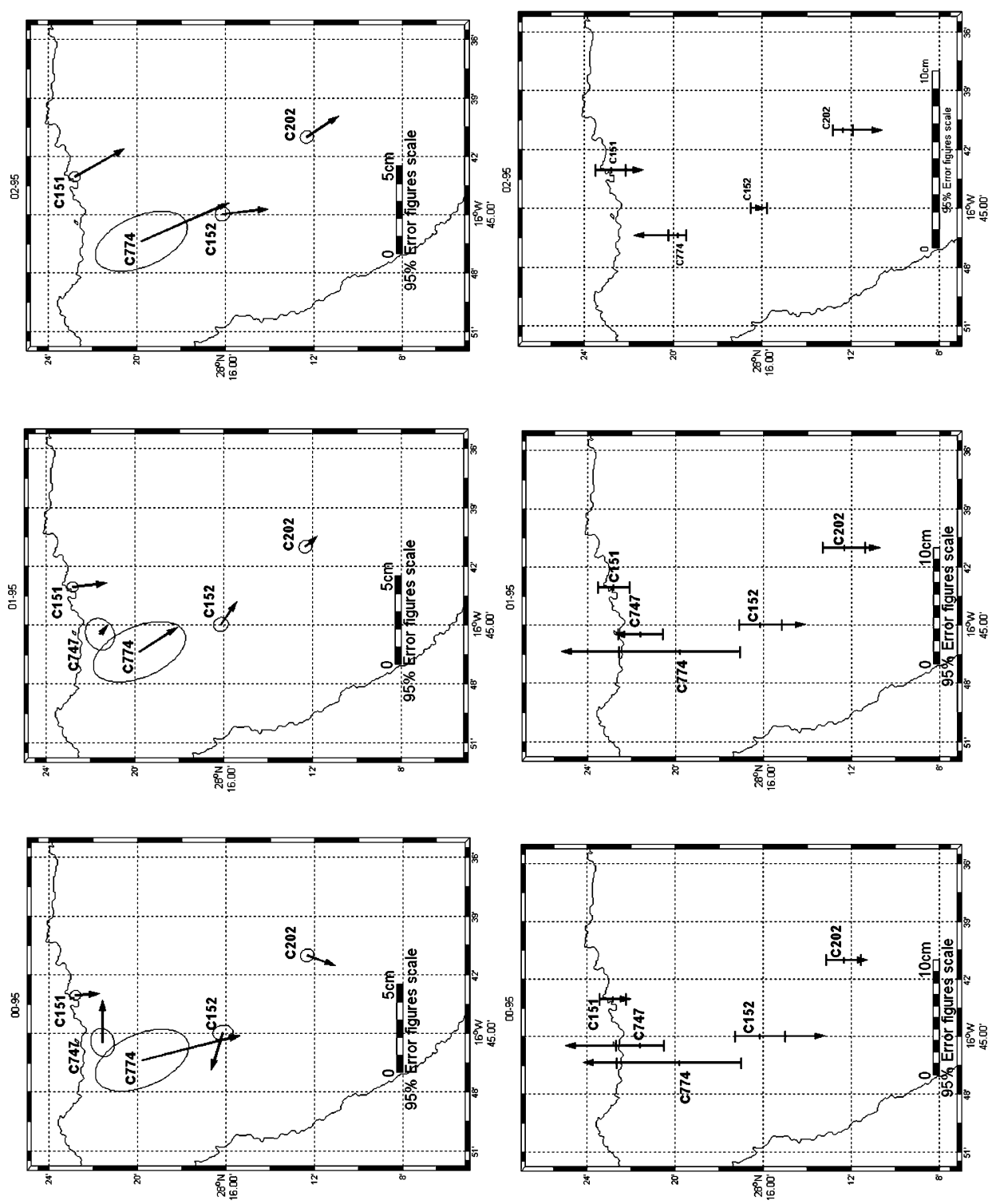

Figure 5

Horizontal and vertical displacement with errors. Vectors with error ellipses for horizontal and with error bars for vertical motions. Differences, given in $\mathrm{cm}$, are computed by comparison of coordinates measured in 1995, 2000, 2001 and 2002 for the repeated stations of the DZs micro-network. For example, 00-95 indicates differences between 2000 and 1995 coordinates. 

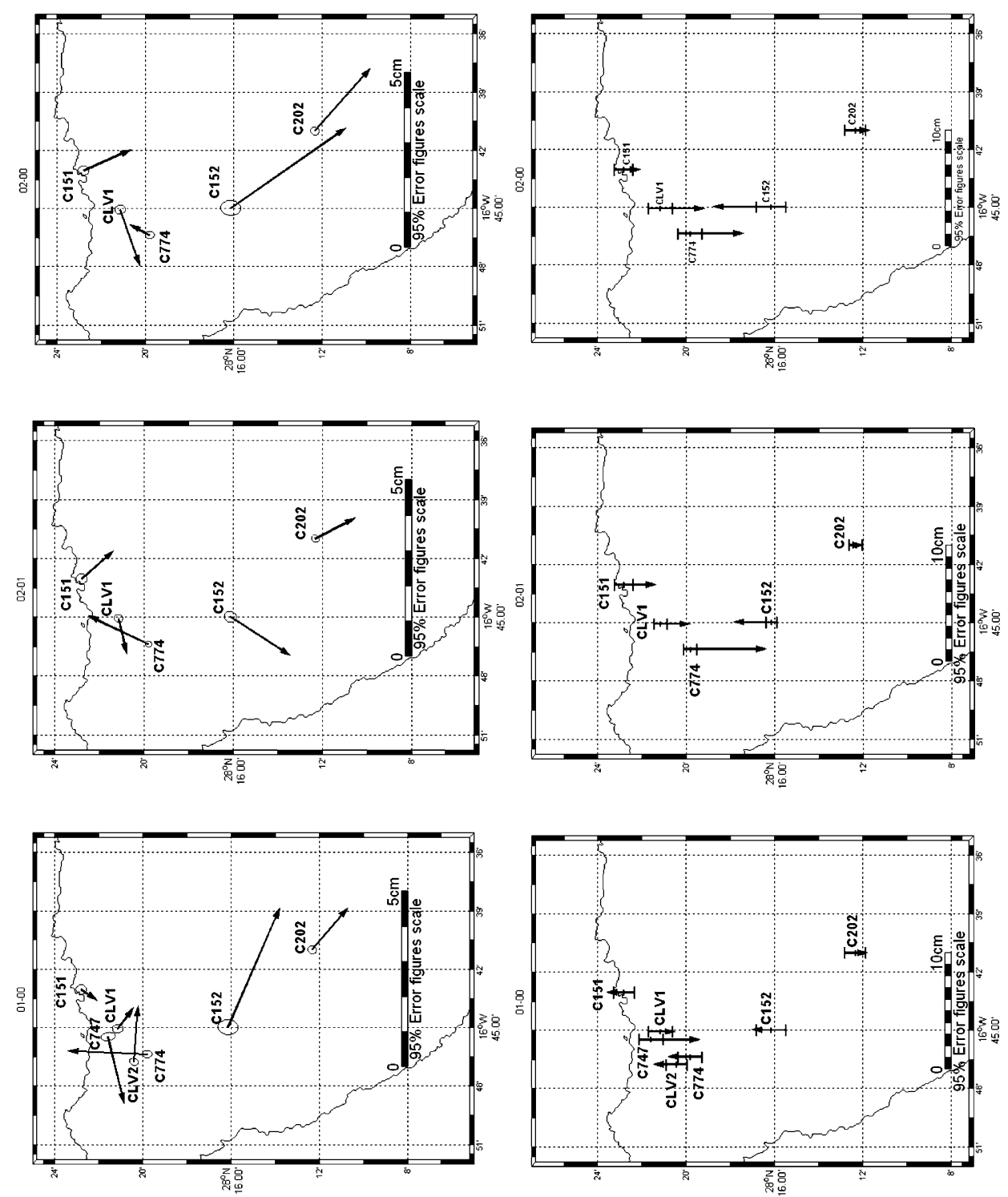

Figure 5

(Contd.)

Tenerife, 1989). At present it is difficult to distinguish the real cause from the others with certainty. Different geodetic and geophysical experiments are being prepared to determine the origin and evolution of the subsidence (FERNÁNDEZ et al., 2002).

The deformations found are located in areas where large amounts of groundwater have been drawn since the end of the 19th century (Government of Canary Islands 
and CABILdo Insular de Tenerife, 1989). Furthermore, since 2000, there has been a clear increase in rainfall on the island (I. Farrujia, personal communication, 2002), as a result of which groundwater levels have risen in some areas of the island, or are dropping more slowly.

This leads us to think that the groundwater decrease/recharge may be at least partly the cause of the displacements observed, as has been seen elsewhere (Kaufmann and Amelung, 2000; Hoffmann et al., 2001; Le Mouélic et al., 2002; WATSON et al., 2002). In order to test this hypothesis, we will endeavor to interpret the displacements using the model developed by GeERTSMA (1973) and used in similar problems by XU et al. (2001) and LE Moú́LIC et al. (2002). We will only consider the vertical component of the displacement in our study. A future, more complete interpretation should also consider the horizontal components. The model assumes that the reservoir is a circular disk of radius $\mathrm{R}$ and height $\mathrm{h}$ buried parallel to the flat earth surface at depth D. The elastic earth is treated as an elastic half-space with Poisson's ratio $\delta$. Then the vertical component of the displacement of the surface $u$ is

$$
u=(2 \delta-2) \Delta h R \int_{0}^{\infty} e^{-D \alpha} J_{1}(\alpha R) J_{0}(\alpha r) d \alpha=(2 \delta-2) \Delta h \mathrm{~A}
$$

where $r$ is the radial coordinate along the surface with origin above the center of the reservoir; $\Delta h$ is the height change of the reservoir due to its recharge or compaction, and $\alpha$ is the integration variable.

For the elastic parameters we could consider those determined by FERNÁNDEZ et al. (1999). They give as properties for the $3.5 \mathrm{~km}$ of the crust in their cortical model (from $2 \mathrm{~km}$ over sea level to $1.5 \mathrm{~km}$ below it) a density of $2100 \mathrm{~kg} \mathrm{~m}^{-3}$, and Lamé parameters $\lambda=8 \cdot 10^{9} \mathrm{~Pa}$ and $\mu=7 \cdot 10^{9} \mathrm{~Pa}$. Therefore the Poisson's ratio is $\delta=0.27$. Furthermore, the information available (CONSEJo InSULAR DE AGUAS DE TENERIFE, 2002) can be used to obtain an approximation of the depth and radius values of the underground aquifers. We will annotate the values of DZ1 with subindex 1 and the value of DZ2 with subindex 2. We derive $D_{1}=0.4 \mathrm{~km}, R_{1}=2 \mathrm{~km}, D_{2}=1.2 \mathrm{~km}$ and $R_{2}=3 \mathrm{~km}$. Using the values tabulated by GEERTSMA (1973) of parameter $A$, see equation (1), as a function of $\rho=r / R$ and $\eta=D / R$, we obtain for $\rho_{1}=\rho_{2}=0$, $\eta_{1}=0.2$ and $\eta_{2}=0.4$, the values $A_{1}=0.8039$ and $A_{2}=0.6286$, which are the maximum vertical deformation $u_{\max }$ in $r=0 \mathrm{~km}$ in DZ1 and DZ2, respectively. Finding the value of (1), we obtain the expression of the water table variation as a function of the deformation in $r=0, u_{\max }, \delta$ and $A$ :

$$
\Delta h=\frac{u_{\max }}{(2 \delta-2) A} .
$$

Replacing the maximum subsidence values in the period 1993-2000 in DZ1 and DZ2, which are around -10 and $-4 \mathrm{~cm}$, respectively (values obtained from the InSAR and GPS results, averaging values in the case of DZ2), we obtain the 
respective water table level variation values for that period $\Delta h_{1}=-8.5 \mathrm{~cm}$ and $\Delta h_{2}=-4.4 \mathrm{~cm}$. However, if we consider the period 2000-2002, the deformation values in DZ1 and DZ2 would now be around -6 and $+4.4 \mathrm{~cm}$, respectively, producing water table variations $\Delta h_{1}=-5 \mathrm{~cm}$ and $\Delta h_{2}=4.8 \mathrm{~cm}$.

\section{Conclusions}

This paper describes the design, observation methodology used and the results of the GPS observation campaign conducted in 2001 in the areas of the N-W of Tenerife, where deformation was detected using InSAR (CARRASCO et al., 2000; FERNÁNDEZ et al., 2002) and discusses possible interpretations.

To avoid undesirable antenna stationing errors in the stations built with nails, we designed and used perfectly numbered and calibrated, fixed-length metal poles, secured with steel cable by means of a turnbuckle and a galvanized flat. This guaranteed that the GPS antenna could be stationed on the control nail with a height repeatability of the order of $1 \mathrm{~mm}$ and below $3 \mathrm{~mm}$ on the horizontal plane. The obtained results guarantee that this system is ideal for field observation, and considerably better than using tripods, especially in areas where, as in Tenerife, one wants to detect small displacements that otherwise might be masked by accidental errors in measuring heights or centering, as was inferred in the 2000 campaign (FERNÁNDEZ et al., 2003).

When the 2001 observations were processed, we found that using different antenna models in the same session can cause errors that can lead to inaccurate results. Therefore the same antenna model was used at all stations in the 2002 campaign. We also observed that, in order to make the data processing and global network adjustment more reliable, one or two stations should be observed in all the sessions. Therefore, it was decided that the fixed station, Regatón, and central station in DZ1, where the highest deformation value is expected, will always be observed in the next campaigns. This was the procedure followed in the 2002 campaign.

The results have reconfirmed the displacement in the Chío deformation zone for the period 1995-2000 and indicate that vertical coordinate increased again from 2000 to 2002. They have drawn attention to the existence of possible displacements at station $\mathrm{C} 202$, next to this zone. The results also confirm that the subsidence detected by InSAR to the south of the Garachico have continued since 2000, and also indicate that the magnitude of the vertical deformation to be expected in the one-year interval has increased from around one $\mathrm{cm}$ a year to more than $3 \mathrm{~cm}$ a year. These values indicate the need to continue monitoring the displacements.

One of the possible reasons for the detected displacements could be the groundwater level variation. A first attempt has been made to model this with a simple model (GEERTSMA, 1973) that can only be regarded as an approximation to the real problem on the Island of Tenerife, due to both to the type of reservoir and 
the medium considered (homogeneous and without fractures). However, the results do not contradict the groundwater level decrease values (GobIERNo DE CANARIAS and Cabildo Insular de Tenerife, 1989) and, in Pinar de Chío are coherent with the increase in rainfall in the recent years (I. FARRUJA, personal communication, 2002). These results seem to indicate that the observed deformation and the groundwater level variation are somehow related. Also, in the case of Pinar de Chío, the deformation measured could also be affected by other factors such as the system of fractures existing in the zone (I. FARRUJA and J. COELLO, personal communication, 2002). Consequently, there is clearly a need to continue with the described research, with further monitoring of the displacements in order to study their evolution; further interpretation using more and different data (gravity, gases, etc.); real, detailed and up-to-date information about the evolution of the ground waters; and the development of models that represent the island's characteristics more accurately. It should also be noted that this research is also very important, not only for studying the displacements that might be associated, at least partly, to the extraction of groundwater, but must be capable of clearly distinguishing them from other displacements on the island's surface that might be linked to a future magmatic reactivation. Once effects of water level variations have been removed or have been shown to be irrelevant, then the continuous monitoring of ground deformation becomes a useful tool for volcanic activity monitoring. When combined with seismic, hydrologic and fumarolic activity, it provides the means to evaluate the physical processes at work, at greater depth.

\section{Acknowledgements}

This research has been funded through the Ministry of Science and Technology project AMB99-1015-C02, ESA-ESRIN Contract No.13661/99/I-DC and the MEDSAR contract with INDRA Espacio SA. We thank the Consejo Insular de Aguas de Tenerife for information regarding groundwater extraction and rainfall. We thank S. Le Mouélic, K.F. Tiampo, I. Farrujia and J. Coello for their useful comments. We are thankful for the review by A. Donnellan, J. Fonseca and F. Cornet which improved this paper.

\section{REFERENCES}

Ablay, G. J. and Marti J, (2000), Structure, Stratigraphy, and Evolution of the Pico Teide-Pico Viejo Formation, Tenerife, Canary Islands, J. Volcanol. Geotherm. Res. 103, 175-208.

Ancochea, E., Fúster J. M., Ibarrola E., Cendrero A., Colllo J., Hernán F., Cantagrel J. M., and JAMOND C, (1990), Volcanic Evolution of the Island of Tenerife (Canary Islands) in the Light of New K-Ar Data, J. Volcanol. Geotherm. Res. 44, 231-249. 
ARAÑA, V. and Ortiz R, The Canary Islands: Tectonics, magmatism and geodynamic framework, In Magmatism in Extensional Structural Settings. The Phanerozoic African Plate (A. B. Kampunzu, and R. T. Lubala, eds.) (Springer-Verlag, Berlin 1991) pp. 209-249.

BALdi, P. and Unguendoli, M., Geodetic networks for crustal movements studies. In (Stuart Turner, (ed.), Lecture Notes in Earth Sciences, 12. Applied Geodesy (Springer-Verlag 1987) pp. 135-161.

Beutler, G., Bock, H., Brockmann, E., Dach, R., Fridez, P., Gurtner, W., Hugentobler, U., Ineichen, D., Johnson, J., Meindl, M., Mervant, L., Rothacher, M., Schaer, S., Springer, T., and WEBER, R. (2001) Bernese GPS Software Version 4.2. (eds. U. Hugentobler, S. Schaer, and P. Fridez.) Astronomical Institute, University of Berne, $515 \mathrm{pp}$.

Bürgmann, R., Rosen, P. A., and Fielding, E. J. (2000), Synthetic Aperture Radar Interferometry to measure Earth's Surface Topography and its Deformation, Ann. Rev. Eath Planet. Sci. 28, 169-209.

Camacho, A. G., Vieira, R., and Toro, C. (1991), Microgravimetric Model of the Las Cañadas Caldera (Tenerife), J. Volcanol. Geotherm. Res. 47, 75-88.

Carrasco, D., Fernández, J., Romero, R., Araña, V., Martínez, A., Moreno, V., Aparicio, A., and PAGANINI, M. (2000), First Results from Operational Volcano Monitoring in the Canary Islands, ESA, SP461, ERS-ENVISAT Symposium, Gothenburg, Sweden 16-20/10/2000. CD-ROM.

CATuRLA, J. L. (1996), REGCAN95, Nueva Red Geodésica de las Islas Canarias., Instituto Geográfico Nacional, Area de Geodesia. Internal Report.

Consejo Insular de Aguas de Tenerife (2002), http://www.aguastenerife.org/sup.html.

Fernández, J., Carrasco, J. M., Rundle, J. B., and Araña, V. (1999), Geodetic Methods for Detecting Volcanic Unrest: A Theoretical Approach, Bull. Volcanol. 60, 534-544.

Fernández, J., Romero, R., CARrasco, D., Luzón, F., Araña, V. (2002), InSAR Volcano and Seismic Monitoring in Spain. Results for the Period 1992-2000 and Possible Interpretations, Optics and Lasers in Engin. 37, 285-297.

Fernández, J., Yu, T.-T., Rodríguez-Velasco, G., Gonzalez-Matesanz, F. J., Romero, R., Rodríguez, G., Quirós, R., Dalda, A., Aparicio, A., and Blanco, M. J. (2003), New Geodetic Monitoring System in the Volcanic Island of Tenerife, Canaries, Spain. Combination of InSAR and GPS Techniques, J. Volcanol. Geotherm. Res. 124, 241-253.

Geertsma, J. (1973), Land Subsidence above Compacting Oil and Gas Reservoirs., J. Pet. Tech. 734-744. Gobierno de Canarlas, Cabildo Insular de Tenerife (1989), Plan hidrológico Insular de Tenerife. Avance: bases para el planeamiento hidrogeológico. Ed. Cab. Insul. de Tenerife, $133 \mathrm{pp}$.

HANSSEN, R. F., Radar Interferometry: Data Interpretation and Error Analysis (Kluwer Academic Publishers, The Netherlands, 2001) $308 \mathrm{pp}$.

Hoffmann, J., Zebker, H. A., Galloway, D. L., and Amelung, F. (2001), Seasonal Subsidence and Rebound in Las Vegas Valley, Nevada, Observed by Synthetic Aperture Radar Interferometry, Water Resources Res. 37, 1551-1566.

Hofmann-Wellenhof, B., Lichteneger, H., and Colins, S. J., GPS Theory and Practice, 2nd edi. (Springer Verlag Wien New York, 1992) $326 \mathrm{pp}$.

Johnson, H. O. and WyatT, F. K. (1994), Geodetic Network Design for Fault-mechanics Studies, Manuscripta geodaetica 19, 309-323.

Kaufmann, G. and Amelung, F. (2000), Reservoir-induced Deformation and Continental Rheology in Vicinity of Lake Mead, Nevada, J. Geophys. Res. 16,341-16,358.

Le Moueleic, S., Raucoules, D., Carnec, C., and King, C. (2002), A Ground Uplift in the City of Paris (France) Detected by Satellite Radar Interferometry, Geophys. Res. Lett. 29, 1853, doi:10.1029/ 2002GL015630.

LeICK, A., GPS Satellite Surveying. (Wiley, New York Chichester Brisbane Toronto Singapore 1990).

Martí, J., Mituavila, J., and Araña, V. (1994), Stratigraphy, Structure and Geochronology of the Las Cañadas Caldera (Tenerife, Canary Islands), Geol. Mag. 131, 715-727.

Massonet, D. and Feigl K. L. (1998), Radar Interferometry and its Application to Changes in the Earth's Surface, Rev. Geophys. 36, 441-500.

Massonnet, D. and Sigmundsson, F. (2000), Remote sensing of volcano deformation by radar interferometry from various satellites. In Remote Sensing of Active Volcanism, Geophysical Monograph 116, AGU, pp. 207-221. 
Puglisi, G. and Coltelli M, (2001), SAR Interferometry Applications on Active Volcanism: State of the Art and Perspectives for Volcano Monitoring, Il Nuovo Cimento 24, 133-145.

Rodríguez-Velasco, G., Romero, R., Yu, T.-T., González-Matesanz, J., Quirós, R., Dalda, A., CARRAsco D., and Fernández, J. (2002), Introducción de técnicas espaciales a los sistemas de vigilancia geodésica en Tenerife (Islas Canarias). Asamblea Hispano-Portuguesa de Geodesia y Geofisica. Valencia (España) 4-8 Febrero 2002. Proceedings Tomo II, Editorial UPV, pp. 746-750.

Segall, P. and Matthews, M. (1997), Time-dependent Inversion of Geodetic Data, J. Geophys. Res. 102, 22,931-22,409.

Sevilla, M. J. and Romero, P. (1991), Ground Deformation Control by Statical Analysis of a Geodetic Network in the Caldera of Teide, J. Volcanol. Geotherm. Res. 47, 65-74.

Sevilla, M. J., Valbuena, J. L., Rodríguez-Díaz, G. and Vara, M. D. (1996), Trabajos altimétricos en la Caldera del Teide, Física de la Tierra 8, 117-130.

Watson, K. M., Bock, Y., and SANDwell, D. (2002), Satellite Interferometric Observation of Displacements Associated with Seasonal Groundwater in the Los Angeles Basin, J. Geophys. Res. 107, B4, 10.1029/2001JB000470.

Xu, H., Dvorkin, J., and Nur, A. (2001), Linking Oil Production to the Surface Subsidence from Satellite Radar Interferometry, Geophys. Res. Lett. 28, 1307-1310.

Yu T.-T., Fernández, J., Tseng, C.-L., Sevilla, M. J., and Araña V. (2000), Sensitivity Test of the Geodetic Network in Las Cañadas Caldera, Tenerife, for Volcano Monitoring, J. Volcanology and Geothermal Res. 103, 393-407. 